\title{
Artaud et les avant-gardes théâtrales, Textes présentés et réunis par Olivier Penot-Lacassagne
}

\section{Emanuele Kanceff}

\section{(2) OpenEdition}

1 Journals

\section{Edizione digitale}

URL: http://journals.openedition.org/studifrancesi/33607

DOI: 10.4000/studifrancesi.33607

ISSN: 2421-5856

\section{Editore}

Rosenberg \& Sellier

\section{Edizione cartacea}

Data di pubblicazione: 1 décembre 2005

Paginazione: 674-675

ISSN: 0039-2944

\section{Notizia bibliografica digitale}

Emanuele Kanceff, «Artaud et les avant-gardes théâtrales, Textes présentés et réunis par Olivier PenotLacassagne», Studi Francesi [Online], 147 (XLX | III) | 2005, online dal 30 novembre 2015, consultato il 19 avril 2021. URL: http://journals.openedition.org/studifrancesi/33607 ; DOI: https://doi.org/10.4000/ studifrancesi.33607

Questo documento è stato generato automaticamente il 19 avril 2021.

\section{(c)}

Studi Francesi è distribuita con Licenza Creative Commons Attribuzione - Non commerciale - Non opere derivate 4.0 Internazionale. 


\title{
Artaud et les avant-gardes théâtrales, Textes présentés et réunis par Olivier Penot-Lacassagne
}

\author{
Emanuele Kanceff
}

\section{NOTIZIA}

AA. VV., Artaud et les avant-gardes théâtrales, Textes présentés et réunis par Olivier PENOTLACASSAGNE, «Antonin Artaud» 2, Paris-Caen, Lettres Modernes Minard, 2005 («La Revue des Lettres Modernes», serie Antonin Artaud, diretta da Olivier Penot-Lacassagne), pp. 193.

1 In considerazione dell'immensa influenza de Le Théâtre et son double ma anche del tempo trascorso, in un denso avant-propos, Olivier PENOT-LACASSAGNe, curatore del volume e della collana, si chiede se si legga ancora Artaud come un riferimento, oppure con semplice spirito protocollare. Il volume tenta di rispondere, con una serie di articoli, a questa interrogazione.

Inizia la serie un noto specialista: Pourquoi le Théâtre Alfred-Jarry? si chiede, sotto forma di lettera datata da Parigi il 15 febbraio 2003, Henri BÉHAR (pp- 9-24), che, attingendo a piene mani ai suoi ricordi di giovane ricercatore, snocciola la storia dei rapporti Artaud-Vitrac, del Théâtre Alfred Jarry e del teatro in Francia negli anni Venti. Isabelle KRZYwKowsICI, "Le côté révélateur de la matière »: masques, mannequins et machines dans le théâtre d'Antonin Artaud (1920-1935) (pp. 25-51) si accosta ad un aspetto caratteristico ed importante, malgrado le prese di posizione teoriche: maschere, marionette e manichini appaiono come macchine da guerra per lottare contro il teatro sclerotizzato del XIX secolo. Inoltre, oggetti reali e legati al corpo, essi posseggono quella materialità di segno che il modello meccanico potrà organizzare. Giorgia BonGIORNo riflette su «Le Drame mental» et l'impossible Théâtre - réflexions sur "Le Jet de sang" (pp. 53-74) e sul processo di captazione e trasformazione che rappresenta questa pièce; mentre Viviane 
BARRY, Artaud, Daumal et le théâtre oriental (pp. 75-85) inizia una trasmigrazione ideale che continua con Guy DUREAU, D'une catastrophe l'autre: le Mexique et la mise en scène de la Cruauté (pp. 89-111). Con Monique BoRIE, Le Théâtre des années Soixante: «l'ère Artaud» (pp. 113-137) si affronta l'argomento decisivo della fortuna di Artaud negli anni Sessanta e del suo reale influsso, mentre con Françoise QUILLET, Ariane Mnouchkine et Antonin Artaud, (pp. 139-157) entriamoinun discorso più dettagliato per scoprire i segreti e non noti rapporti tra i due personaggi. Anche il capitolo "orientale" conosce suggestivi prolungamenti con Artaud et le Japon: pour une histoire du théâtre transnationale, di Mari SAKAIIARA. pp. 159-166. Il curatore del voume, Olivier PENOT-LACASSAGNE, completa il quadro internazionale con Artaud et les pratiques théâtrales contemporaines: l'exemple de la Slovénie (pp. 167-182). Conclude il volume un poetico testo sul «désordre créateur» del «travailleur des ténébres», Artaud, le vertige de l'acteur, di Pierre-Antoine VILLEMAINE (pp. 183-192), che ripercorre poeticamente il percorso che è sboccato sulla creazione del linguaggio. 